\title{
SEGURANÇA DA POSSE: ELEMENTO ESSENCIAL À EFETIVAÇÃO PLENA DO DIREITO FUNDAMENTAL À MORADIA
}

\section{SECURITY OF TENURE: ESSENTIAL ELEMENT TO EFFECTIVE FULL OF FUNDAMENTAL RIGHT TO HOUSING}

\author{
SABRINE TAMS GASPERIN \\ Advogada, graduada em Direito pela Universidade Federal de Pelotas-RS \\ binagasper@gmail.com
}

\begin{abstract}
RESUMO
Com o presente estudo, pretende-se demonstrar que a segurança da posse é elemento essencial na garantia do direito fundamental à moradia. Desta forma, aborda-se na perspectiva de que tal garantia pode ser assegurada através de instrumentos urbanísticos previstos no Estatuto da Cidade e na Lei 11.977/2009, como a usucapião administrativa, delimitação de Zonas Especiais de Interesse Social e as Concessões de Uso por parte do Poder Público.
\end{abstract}

Palavras-chave: Direito à Moradia; Instrumentos Urbanísticos; Segurança da Posse.

\begin{abstract}
With this study, we intend to demonstrate that security of tenure is an essential element in ensuring the fundamental right to property. Thus, we address the prospect that such a guarantee can be ensured through urban planning instruments under the Statute of the City and Law $11.977 / 2009$, as administrative usurpation, delineation of Special Zones of Social Interest and concessions by the Power Usage public.
\end{abstract}

Keywords: Right to Housing; Urbanísticos instruments; Security of Tenure.

\section{SUMÁRIO}

INTRODUÇAO; 1 SEGURANÇA DA POSSE COMO ELEMENTO ESSENCIAL À EFETIVAÇÃO PLENA DO DIREITO FUNDAMENTAL À MORADIA; 1.1 Instrumentos de Regularização Fundiária; 1.1.1 Delimitação de Zonas Especiais de Interesse Social; 1.1.2 Demarcação Urbanística, Legitimação de posse e a Usucapião Administrativa; 1.1.3 Concessão de uso especial para fins de moradia e Concessão de direito real de uso; 2 PAPEL DO PODER PÚBLICO NA GARANTIA DA SEGURANÇA DA POSSE E EFETIVAÇÃO DO DIREITO À MORADIA; CONCLUSÃO; REFERÊNCIAS.

\section{INTRODUÇÃO}

Dados do UN-Habitat informam que mais de um bilhão de pessoas residem em assentamentos precários ou favelas, e, consequentemente, sem disponibilidade de serviços básicos e sem condições de vida adequada. Ou seja, grande parte da população mundial 
sobrevive em razão da posse. Desta constatação sobrevém a justificativa da presente pesquisa conforme será aprofundado no decorrer do trabalho.

O objetivo geral do presente estudo é analisar, a partir de pesquisa bibliográfica, os mecanismos disponíveis à regularização fundiária como meios de garantia da proteção da posse e consequentemente tutela do direito à moradia. Os instrumentos de regularização fundiária utilizados para exposição e análise formam um rol estritamente exemplificativo, visto que atualmente existem múltiplas possibilidades apresentadas tanto na Lei 10.257/01 como na Lei 11.977/09. A escolha dos instrumentos apresentados (zonas especiais de interesse social, demarcação urbanística, legitimação, usucapião administrativa e as concessões de uso) se deu em razão de sua praticidade e operacionalidade simplificada, por demandar exclusivamente do impulso administrativo do Executivo.

Neste sentido, o presente trabalho estrutura-se em dois capítulos, sendo que o primeiro versa sobre a importância da segurança da posse para tutela do direito à moradia, de forma a esclarecer e expor os mecanismos urbanísticos disponíveis para assegurar o exercício regular da posse sobre imóveis urbanos. Já no segundo capítulo, faz-se uma breve explanação sobre o dever constitucional do Poder Público Municipal em concretizar a regularização fundiária nos Municípios, demonstrando-se a essencialidade de sua intervenção para segurança da posse e consequente efetivação do direito à moradia.

\section{SEGURANÇA DA POSSE COMO ELEMENTO ESSENCIAL À EFETIVAÇÃO PLENA DO DIREITO FUNDAMENTAL À MORADIA}

A ocupação do solo no Brasil deu-se de forma desordenada em razão de falta de planejamento urbano, assim como milhões de pessoas tiveram de ocupar áreas públicas ou privadas na garantia de seu mínimo existencial. Nesta circunstância, o urbano em nosso país fora dividido na cidade informal e a formal.

As áreas denominadas "assentamentos informais" são fruto da negligência do Estado que, muitas vezes, se omiti em planejar e instituir políticas públicas de produção de habitação para baixa renda. Atualmente as populações dos assentamentos informais padecem com a fragilidade da moradia irregular e/ou clandestina.

Ocorre que as famílias de baixa renda que ocupam estas áreas para fins de moradia, conquistaram, pelo tempo transcorrido, o direito ao reconhecimento daquele local como sua 
moradia, pois deram função social à propriedade que até então se encontrava abandonada, vazia ou ociosa.

É dever do Estado, neste contexto, utilizar os mecanismos dispostos na Constituição Federal ou mesmo em leis esparsas, como o Estatuto da Cidade e a Medida Provisória $\mathrm{n}^{\circ}$ 2.200/2001, com a viabilização do reconhecimento destas áreas por usucapião de área privadas ou mesmo com a concessão de uso especial para fins de moradia de áreas públicas, garantindo assim a segurança da posse dessas áreas consolidadas na história.

A regularização fundiária dos assentamentos informais garante a segurança da posse e a qualidade de vida dos cidadãos então existentes. 0 título do lote, com o devido registro, põe fim ao risco de despejos inesperados ou outras ameaças, fazendo com que não se perca tudo que fora consolidado e enraizado objetiva e subjetivamente pela família ali organizada. Conforme Edésio Fernandes:

\begin{abstract}
Títulos são importantes, sobretudo quando há conflitos, sejam eles conflitos de propriedade, conflitos domésticos e familiares, conflitos de direito de vizinhança, etc. Títulos também são importantes para reconhecer direitos sociopolíticos e para garantir que os ocupantes dos assentamentos informais possam permanecer nas áreas que ocupam, sem risco de serem expulsos pela ação do mercado imobiliário, por mudanças políticas que quebrem o pacto gerador da percepção de segurança de posse, pela pressão do crime organizado, etc., como tem acontecido em diversas favelas e loteamentos irregulares brasileiros $^{1}$.
\end{abstract}

Em relação ao conceito de segurança da posse, temos como mais satisfatório documento escrito, o informe da relatora especial da ONU sobre direito à moradia adequada, Raquel Rolnik, que apresentou estudo aprofundado sobre o tema em 24 de dezembro de 2012 na $22^{\text {a }}$ Sessão do Conselho de Direitos Humanos da referida Instituição Internacional.

No estudo realizado foi apresentada a segurança da posse como componente do direito à moradia adequada, levantando questões sobre as obrigações objetivas dos Estados em relação ao conceito apresentado na prática. Desta forma, definiu-o como sendo a garantia da proteção legal contra remoções forçadas, assédios e outras ameaças.

A segurança da posse garante o pleno desenvolvimento social das comunidades, assim como assegura aos grupos mais vulneráveis o direito à dignidade humana e inibe violações aos direitos humanos, conforme expressa a Relatora:

\footnotetext{
${ }^{1}$ FERNANDES, Edésio. Regularização de assentamentos informais: o grande desafio dos governos e da sociedade. In: CARVALHO, Celso Santos (coord). Acesso à terra urbanizada: implementação de planos diretores e regularização fundiária plena. Florianópolis: UFSC; Brasília: Ministério das Cidades, 2008. p. 366.
} 
En cambio, cuando se garantiza el acceso a una vivienda o tierras en condiciones de seguridad, el potencial de progreso económico y social es inmenso, lo cual se ha reconocido a nivel mundial. La seguridad de la tenencia es muy importante para las familias y los particulares. Ofrece a las personas certidumbre en cuanto a lo que pueden hacer con sus tierras o su vivienda, y también brinda protección contra las intromisiones de terceros. Muchas veces protege, aumenta y posibilita el acceso a servicios y prestaciones de carácter público. Incrementa las oportunidades económicas y sirve de base para el empoderamiento económico de la mujer y su protección contra la violencia. La importancia de esta cuestión, no solo para los derechos humanos sino también para el desarrollo, es evidente ${ }^{2}$.

Neste sentido, a segurança da posse deve ser compreendida em quatro aspectos, conforme delimitado pelo informe da Relatoria de Direito à Moradia Adequada da Organização das Nações Unidas:

la Relatora Especial subraya que la seguridad de la tenencia debe entenderse como un concepto que engloba, como mínimo: a) la protección jurídica contra el desalojo forzoso, el hostigamiento y otras amenazas; b) el reconocimiento jurídico por las autoridades, pero también por los agentes privados, del derecho a vivir en un lugar seguro en condiciones de paz y dignidad; ese reconocimiento comprende el apoyo de las autoridades y un acceso equitativo a todos los servicios públicos y la disponibilidad de estos; c) la justiciabilidad; o, dicho de otro modo, la capacidad de exigir por la vía legal la seguridad de la tenencia; para que ese critério sea verdaderamente efectivo puede ser necesario prestar asistencia jurídica con miras a facilitar el acceso a medidas de recurso eficaces; y d) cualquier otro aspecto que se requiera como medida susceptible de facilitar el disfrute de otros aspectos del derecho a una vivienda adecuada en pie de igualdad con el resto de los ciudadanos ${ }^{3}$.

Além disso, a relatora da ONU elencou de forma aprofundada diversos entraves à garantia da segurança da posse, com a análise de vários aspectos como a governança e economia politica da terra, o ordenamento do território, a administração da terra, o papel das terras públicas, o planejamento urbano, o reconhecimento e registro das mais diversas formas de posse.

Em síntese, a segurança da posse é um elemento essencial do direito à moradia e à terra já que sem ela o direito à moradia vai estar em permanente ameaça, e o risco de despejo ou deslocamento forçado será iminente. A segurança da posse, por se tratar de ponto central do direito humano à moradia, deve ser garantida a todos e todas, com igualdade e sem

\footnotetext{
2 ROLNIK, Raquel. Informe de la Relatora Especial sobre uma vivenda adecuada como elemento integrante del derecho a um nível de vida adecuado y sobre el derecho de no discriminación a este respecto. $2012 . \quad$ Disponível em: <http://www.ohchr.org/Documents/HRBodies/HRCouncil/RegularSession/Session22/A.HRC.22.46_sp.pdf>. Acessado em: 25 de mar. de 2014. p.6.

${ }^{3}$ ROLNIK, ibid., p.7.
} 
discriminação, alcançando todos os indivíduos e famílias independentemente de idade, status econômico, grupo ou outra afiliação e status (OSÓRIO, 2006).

Para tal garantia, é imprescindível que o Estado reconheça de forma legal a diversidade de formas de uso e ocupação do solo presentes nas áreas urbanas (ocupação de área pública, prédios abandonados, lote irregular, etc) por meio de normas nacionais de direito à moradia, como também, devem assegurar o acesso a recursos legais de forma gratuita, para população de baixa renda, a fim de remediar despejos ocorridos ou outras formas de violação ao direito à moradia (OSÓRIO, 2006).

\subsection{Instrumentos de Regularização Fundiária}

Previamente faz-se necessário esclarecer que regularização fundiária é o processo de transformação de moradias informais em moradias legalizadas, com registro no cartório de registro de imóveis, adequação à infraestrutura elementar e implementação de serviços públicos básicos (escola, hospitais, praças) no entorno do assentamento, melhorando a qualidade de todos os que vivem na localidade.

Para Edésio Fernandes

O termo "regularização" tem sido usado pelas diversas municipalidades com sentidos diferentes, referindo-se em muitos casos somente à urbanização das áreas informais, isto é, aos programas de implementação de obras de infraestrutura urbana e prestação de serviços públicos. Em outros casos, o termo é usado para se referir tão-somente às políticas de legalização fundiária das áreas e dos lotes ocupados informalmente. Algumas experiências mais compreensivas tentam combinar, em alguma medida, essas duas dimensões fundamentais, quais sejam, urbanização e legalização. São ainda mais raros os programas que têm se proposto a promover a regularização das construções informais ${ }^{4}$.

Sendo assim, como já afirmado anteriormente, resta clara a necessidade dos Municípios efetivarem planos de regularização fundiária plena, ou seja, com objetivo do reconhecimento da segurança individual da posse para os moradores, assim como a inclusão socioespacial dos assentamentos informais (FERNANDES, 2007).

\footnotetext{
${ }^{4}$ FERNANDES, Edésio. Perspectivas para renovação das políticas de legalização das favelas no Brasil. Brasília: Ministério das Cidades, 2007. Disponível em: <http://www.urbanismo.caop.mp.pr.gov.br/arquivos/File/Livro_Regularizacao_Fundiaria_Plena_Referenc ias_Conceituais.pdf> Acessado em: 04 de mar. de 2014. p. 21.
} 
Neste sentido, reafirma Raquel Rolnik:

As políticas de regularização fundiária não podem ser formuladas de maneira isolada e necessitam ser combinadas com outras políticas públicas preventivas, para quebrar o ciclo de exclusão que tem gerado a informalidade. Isso requer intervenção direta e investimento público, sobretudo por parte dos municípios, para produzir novas opções de moradia, democratizar o acesso à terra e promover reforma urbana ampla ${ }^{5}$.

No excerto abaixo, extraído da obra de Edésio Fernandes, fica demonstrada a possibilidade de assegurar-se a posse aos ocupantes de assentamentos irregulares consolidados, mesmo sem o reconhecimento formal do direito individual de propriedade:

Em relação aos instrumentos jurídicos a serem utilizados, mesmo que a divisão entre direito público/direito privado tenha de ser considerada, em alguma medida, devido às implicações distintas das propostas, em função do regime de propriedade original das áreas ocupadas, é preciso que os formuladores de programas de regularização se lembrem de que há um leque amplo de opções jurídico-políticas a serem consideradas, além dos direitos individuais de propriedade plena. Sobretudo, é preciso destacar que a materialização do direito social de moradia, tal como consagrado constitucionalmente, não implica, necessariamente, $\mathrm{o}$ reconhecimento de direitos individuais de propriedade, principalmente nos assentamentos em áreas públicas ${ }^{6}$.

Os instrumentos de regularização que possibilitam o exposto pelo Jurista Edésio Fernandes são a concessão de direito real de uso ou de uso especial para fins de moradia de áreas públicas, assim como a legitimação de posse nas áreas privadas (instrumentos que serão analisados detidamente no decorrer deste trabalho).

Para mais, o Estatuto da Cidade trouxe inovações no sentido de viabilizar a utilização dos instrumentos urbanísticos coletivamente, além de trazer a inovação da possibilidade de demarcação das Zonas Especiais de Interesse Social (ZEIS):

Além de regulamentar os institutos já existentes do usucapião especial urbano e da concessão de direito real de uso, que devem ser preferencialmente usados pelos municípios para a regularização das ocupações respectivamente em áreas privadas e em áreas públicas, a nova lei avançou no sentido de admitir a

\footnotetext{
${ }^{5}$ ROLNIK, Raquel. Como mapear as áreas irregulares. In: ALFONSIN, Betânia de Moraes Et al (coord.). Regularização da Terra e Moradia: o que é e como implementar. São Paulo: Instituo Polis, 2002. Disponível em: <http://www.polis.org.br/uploads/949/949.pdf> Acessado em: 24 de jan. de 2014. p.22.

${ }^{6}$ FERNANDES, Edésio. Perspectivas para renovação das políticas de legalização das favelas no Brasil. Brasília: Ministério das Cidades, 2007. Disponível em: <http://www.urbanismo.caop.mp.pr.gov.br/arquivos/File/Livro_Regularizacao_Fundiaria_Plena_Referenc ias_Conceituais.pdf> Acessado em: 04 de mar. de 2014.p.25.
} 
utilização de tais instrumentos de forma coletiva. Ênfase especial foi colocada na demarcação das Zonas Especiais de Interesse Social ${ }^{7}$.

Em suma, a regularização fundiária garante a segurança na posse, inibindo as possíveis ameaças de remoção, além de tornar o local reconhecido juridicamente para a sociedade em geral e para o Município, possibilitando aos moradores a reivindicação de melhorias. Nesta circunstância, a Prefeitura obriga-se a realizar serviços públicos como a coleta de lixo, a limpeza de ruas, as obras de saneamento, escola, posto de saúde, etc.

\subsubsection{Delimitação de Zonas Especiais de Interesse Social}

Para clarificar o entendimento em relação às Zonas Especiais de Interesse Social, inicialmente reporta-se as definições de Betânia Alfonsin:

Para efeito de regularização fundiária, percebeu-se que o zoneamento, como instrumento jurídico e urbanístico, podia ser flexionado de mais de uma forma. Uma delas é aquela que em diferentes cidades brasileiras, em diferentes épocas, disciplinou o zoneamento a partir de interesses econômicos e políticos em favor do mercado imobiliário. Outra possibilidade de utilização do instrumento seria respeitar o contexto imposto por necessidades sociais as quais conduziram determinada parte da população a instalar-se num espaço da cidade que a própria comunidade zoneou, por exemplo, para a sua moradia, coagida por invencível estado de necessidade, gerando o conflito entre a cidade legal e a cidade real.

A criação de ZEIS, assim, no contexto do zoneamento geral, visa a reconhecer como legal essa segunda forma de ocupação do solo urbano. Regulariza, pois, essa forma, como apropriada ao local, com normas específicas e, às vezes, excepcionais, forjadas a partir das características próprias do assentamento. É um instrumento claramente identificado, então, com a regularização urbanística da área, como vimos, uma dimensão fundamental da regularização fundiária ${ }^{8}$.

O Estatuto da Cidade (2001) inovou em inserir as Zonas Especiais de Interesse Social no rol de instrumentos de política urbana. Entretanto, na referida lei não houve sua clara e precisa definição. Apenas em 2009, com a Lei 11.977 (Programa governamental Minha Casa Minha Vida)

\footnotetext{
${ }^{7}$ FERNANDES, Edésio. O Estatuto da Cidade e a Ordem Jurídico-Urbanística. In: Estatuto da Cidade Comentado. CARVALHO, Celso Santos e ROSSBACH, Ana Claudia (org.). São Paulo: Ministério das Cidades, 2010, p.64.

${ }^{8}$ ALFONSIN, Betânia. O significado do Estatuto da Cidade para os processos de regularização fundiária no Brasil. In: Regularização fundiária sustentável: conceitos e diretrizes. Brasília: Ministério das Cidades, 2007.

em: <http://www.urbanismo.caop.mp.pr.gov.br/arquivos/File/Livro_Regularizacao_Fundiaria_Plena_Referenc ias_Conceituais.pdf>. Acessado em: 24 de mar. de 2014. p.83.
} 
a ZEIS fora definida no Art. 47, inciso V, como sendo "parcela de área urbana instituída pelo Plano Diretor ou definida por outra lei municipal, destinada predominantemente à moradia de população de baixa renda e sujeita a regras específicas de parcelamento, uso e ocupação do solo".

Ainda, de acordo com Ancona, fica explicitado que

no processo de construção de uma nova ordem urbanística, fundada no princípio da função social da propriedade, as ZEIS se consolidaram como um tipo especial de zoneamento, cujo principal objetivo é a inclusão da população de menor renda no direito à cidade e à terra urbana servida de equipamentos e infraestrutura, tanto por meio da delimitação de áreas previamente ocupadas por assentamentos precários, quanto por meio da delimitação de vazios urbanos e de imóveis subutilizados, destinados à produção de novas moradias populares ${ }^{9}$.

Aliás, também faz-se importante ressaltar a característica de reconhecimento das mais diversas tipologias urbanas, garantindo às populações originárias a permanência no local com suas características próprias de ocupação, conforme preceitua Alfonsin:

Parece-nos que as zeis conseguem garantir igualdade e diferença às populações moradoras dos assentamentos informais. Garantem, por um lado, o "direito à igualdade", na medida em que o gravame de zeis reconhece e busca consolidar o assentamento no território urbano, garantindo direito à cidade, direito à moradia digna e direito à habitabilidade, independentemente dos interesses que o mercado imobiliário possa ter na localização do assentamento. Por outro lado, também garantem o "direito à diferença", pois reconhecem o processo histórico de produção social e cultural do habitat que redundou em usos, tipologias e padrões irregulares segundo a legislação urbanística do Município para a região, fazendo nascer o direito de utilizar padrões que, ainda que distintos dos estabelecidos pela lei garantam dignidade e habitabilidade aos assentamentos ${ }^{10}$.

Em outro sentido, garante a segurança da posse às populações de baixa renda, consolidando exclusivamente as moradias de interesse social, consoante explanado por Betânia Alfonsin:

Quando o instrumento é utilizado com suas finalidades clássicas em processos de regularização fundiária, ele também tem efeitos sobre o mercado imobiliário,

9 ANCONA, Ana Lúcia. Como delimitar e regulamentar Zonas Especiais de Interesse Social. Brasília: Ministério das Cidades, 2009.2 Disponível <http://www.sst.sc.gov.br/arquivos/id_submenu/230/guia_zeis_final.pdf>. Acessado em: 25 de mar. de 2014. p. 17.

${ }^{10}$ ALFONSIN, Betânia. O significado do Estatuto da Cidade para os processos de regularização fundiária no Brasil. In: Regularização fundiária sustentável: conceitos e diretrizes. Brasília: Ministério das Cidades, 2007.

Disponível

em: <http://www.urbanismo.caop.mp.pr.gov.br/arquivos/File/Livro_Regularizacao_Fundiaria_Plena_Referenc ias_Conceituais.pdf >. Acessado em: 24 de mar. de 2014. p. 84. 
pois ao gravar uma parte do território da cidade, como destinada à manutenção ou produção de habitação de interesse social (his), o Poder Público impede que o mercado imobiliário aproprie-se das intervenções da política habitacional e as desconstrua. 0 gravame de aeis inibe a iniciativa do mercado imobiliário, pois ainda que não haja uma vedação de alienação ex post das unidades habitacionais ou lotes, a área gravada fica vinculada a um uso de interesse social, fazendo com que se dissipe qualquer interesse do mercado imobiliário na área.

Esse efeito de proteção da regularização pela via do gravame de aeis é ainda mais importante nos casos em que o instrumento jurídico de regularização é a usucapião, pois, nesses casos, as famílias têm um título pleno de propriedade e o esforço por garantir a segurança da posse e do direito à moradia pode se esvaecer na volatilidade e possibilidade de circulação econômica do bem regularizado. Ao minimizar o interesse do mercado imobiliário pela área, as aeis acabam cumprindo também com um papel de incremento da segurança da posse do morador, no momento pós regularização fundiária ${ }^{11}$.

Sendo assim, fica clara a contribuição que a delimitação de Zonas Especiais de Interesse Social traz para a concretização material do direito à moradia, bem como para a garantia da segurança da posse para as populações de baixa renda.

\subsubsection{Demarcação Urbanística, Legitimação de posse e a Usucapião Administrativa}

A demarcação urbanística é a delimitação de uma área ocupada para fins habitacionais, de domínio público ou privado, por meio da identificação de seus limites geográficos, confrontantes, área de superfície e localização, com fins de realização posterior de regularização fundiária de interesse social (REGULARIZAÇÃO FUNDIÁRIA URBANA, 2012).

Já a legitimação de posse foi prevista como sendo um instrumento urbanístico a ser utilizado pelos Municípios a fim de identificar áreas ocupadas por pessoas que não possuem título de propriedade ou de concessão e que não sejam foreiras de outro imóvel urbano ou rural, posse esta que deve estar sendo exercida de forma mansa e pacífica. 0 objetivo do instrumento é tornar público as posses identificadas e qualificadas, por meio da emissão de título, em nome do morador, e de seu registro no cartório de registro de imóveis (REGULARIZAÇÃO FUNDIÁRIA URBANA, 2012).

\footnotetext{
${ }^{11}$ ALFONSIN, Betânia. O significado do Estatuto da Cidade para os processos de regularização fundiária no Brasil. In: Regularização fundiária sustentável: conceitos e diretrizes. Brasília: Ministério das Cidades, 2007.

Disponível

em: <http://www.urbanismo.caop.mp.pr.gov.br/arquivos/File/Livro_Regularizacao_Fundiaria_Plena_Referenc ias_Conceituais.pdf $>$. Acessado em: 24 de mar. de 2014. p. 85.
} 
Igualmente, quando não há viabilidade de identificar individualmente os terrenos, é possível suscitar a legitimação de posse coletiva. Nestas circunstâncias, o lote poderá ter mais de $250 \mathrm{~m}^{2}$, desde que a fração ideal de cada ocupante não ultrapasse essa dimensão.

Estes instrumentos foram inovações trazidas pela Lei 11.977 de 2009, in verbis ${ }^{12}$ :

Art. 47. Para efeitos da regularização fundiária de assentamentos urbanos, consideram-se:

III - demarcação urbanística: procedimento administrativo pelo qual o poder público, no âmbito da regularização fundiária de interesse social, demarca imóvel de domínio público ou privado, definindo seus limites, área, localização e confrontantes, com a finalidade de identificar seus ocupantes e qualificar a natureza e o tempo das respectivas posses;

IV - legitimação de posse: ato do poder público destinado a conferir título de reconhecimento de posse de imóvel objeto de demarcação urbanística, com a identificação do ocupante e do tempo e natureza da posse;

Sua aplicação é restrita à regularização fundiária de interesse social e foram introduzidos a fim de garantir de forma mais célere e concreta o direito à moradia, assegurando a posse dos ocupantes de assentamentos já consolidados.

A legitimação de posse realizada em áreas privadas possibilita a aquisição de propriedade por meio da usucapião administrativa. Já quando tiver por objeto área pública, poderá facilitar posterior instrução de pedido de concessão de uso para fins de moradia ou de outros instrumentos definidos pelo titular do domínio da área (REGULARIZAÇÃO FUNDIÁRIA URBANA, 2012).

Neste sentido, é de relevância mencionar que antes da aprovação da Lei $n^{\circ}$ 11.977/2009, a aquisição de imóvel por usucapião se operava apenas pela via judicial, independentemente da modalidade. Com a inauguração dos procedimentos de demarcação urbanística e legitimação de posse em áreas privadas, foi possibilitado que a usucapião especial de imóvel urbano seja realizada totalmente pela via administrativa, ou seja, extrajudicial. Neste processo estão envolvidos os beneficiários, o Poder Público promotor da regularização fundiária de interesse social e o cartório de registro de imóveis da circunscrição imobiliária onde se localize o imóvel (REGULARIZAÇÃO FUNDIÁRIA URBANA, 2012).

Tal possibilidade está prevista no Art. 60 da referida Lei ${ }^{13}$ :

\footnotetext{
12 LEI N 11.977 , de 7 de Julho de 2009. Disponível em: <http://www.planalto.gov.br/ccivil_03/_ato20072010/2009/lei//11977.htm>. Acessado em: $10 \mathrm{de} \mathrm{fev.} \mathrm{de} 2014$.

${ }^{13}$ LEI No 11.977, de 7 de Julho de 2009. Disponível em: <http://www.planalto.gov.br/ccivil_03/_ato20072010/2009/lei//11977.htm>. Acessado em: $10 \mathrm{de} \mathrm{fev.} \mathrm{de} 2014$.
} 
Art. 60. Sem prejuízo dos direitos decorrentes da posse exercida anteriormente, o detentor do título de legitimação de posse, após 5 (cinco) anos de seu registro, poderá requerer ao oficial de registro de imóveis a conversão desse título em registro de propriedade, tendo em vista sua aquisição por usucapião, nos termos do art. 183 da Constituição Federal.

$\S 1^{\circ}$ Para requerer a conversão prevista no caput, o adquirente deverá apresentar:

I - certidões do cartório distribuidor demonstrando a inexistência de ações em andamento que versem sobre a posse ou a propriedade do imóvel;

II - declaração de que não possui outro imóvel urbano ou rural;

III - declaração de que o imóvel é utilizado para sua moradia ou de sua família; e

IV - declaração de que não teve reconhecido anteriormente o direito à usucapião de imóveis em áreas urbanas.

Conforme Venício Salles (2011), a usucapião administrativa representa uma forma para o reconhecimento do perecimento do direito de propriedade pela inércia ou descaso de seu titular, por exigir que o proprietário seja notificado, pessoal ou fictamente, quando da averbação do auto de demarcação, podendo promover impugnação. Ademais, dispõe de cinco anos, contados do registro da legitimação de posse, para reclamar ou reivindicar sua propriedade.

De acordo com o manual institucional do Ministério das Cidades, no qual se demonstra os meios de aplicação da Lei $\mathrm{n}^{\circ} 11.977 / 2009$, a aquisição da propriedade pela usucapião administrativa decorre do preenchimento dos requisitos já previstos na Constituição para a usucapião especial urbana:

Sem prejuízo do tempo de posse anterior, a legitimação registrada no cartório de registro de imóveis dá publicidade à posse mansa, pacífica, ininterrupta e sem oposição, daquele que não seja concessionário, foreiro ou proprietário de outro imóvel urbano ou rural, nem tenha sido beneficiado por legitimação de posse anterior.

Decorrido o prazo de prescrição aquisitiva sem oposição, conforme a modalidade de usucapião, o beneficiário do título de legitimação registrado pode obter a propriedade diretamente no cartório de registro de imóveis, mediante apresentação e análise, pelo oficial de registro dos documentos que comprovem atendimento aos requisitos ${ }^{14}$.

Em síntese, estes mecanismos têm por objetivo a celeridade de procedimentos tradicionalmente burocráticos, de forma a impulsionar a regularização, assegurar a proteção da

\footnotetext{
${ }^{14}$ REGULARIZAÇÃO FUNDIÁRIA URBANA: como aplicar a Lei Federal $n^{\circ} 11.977 / 2009$ - Ministério das Cidades, Secretaria Nacional de Habitação e Secretaria Nacional de Acessibilidade e Programas Urbanos. Brasília, 2012. Disponível em:

<http://www.urbanismo.caop.mp.pr.gov.br/arquivos/File/Regularizacao_Fundiaria/cartilha_11977.pdf>. Acessado em: 25 de fev. de 2014.p.39.
} 
posse e consequentemente a garantia do direito à moradia às populações ocupantes de assentamentos irregulares consolidados, representando um promissor passo para reforma urbana.

\subsubsection{Concessão de uso especial para fins de moradia e Concessão de direito real de uso}

O Estatuto da Cidade trouxe a previsão de dois modos de concessão de uso, a de direito real e a de uso especial para fins de moradia, conforme Betânia Alfonsin:

Inseridos no Estatuto da Cidade, ambos são instrumentos jurídicos de Direito Urbanístico, que outorgam direitos de uso e se aperfeiçoam por um contrato administrativo. O uso, como um dos poderes destacáveis da propriedade, será sempre um direito real, como prevê, aliás, de forma expressa, o Código Civil em seu art. 674, IV, por isso que não pode residir aí a distinção ${ }^{15}$.

A fundamental distinção entre os instrumentos deve ser ressaltada, já que a concessão de uso especial para fins de moradia está restrita à garantia do direito à moradia e tem limites claros, assim como características específicas definidas em lei. Diferentemente é o caso da concessão de direito real de uso, a qual poderá ser utilizada nas mais diversas situações e finalidade urbanísticas em geral, inclusive para fins de moradia (ALFONSIN, 2007).

No que tange à concessão de direito real de uso o Estatuto da Cidade não foi tão abrangente em especificações, tratando a matéria de forma mais sintética. Conforme já mencionado, inclui a concessão de direito real de uso entre os instrumentos jurídicos e políticos da política urbana. O tratamento da matéria, contudo, foi remetido para legislação própria, embora estipule que nos casos de programas e projetos habitacionais de interesse social desenvolvidos por órgãos ou entidades da Administração Pública, com atuação específica nessa área, a concessão de direito real de uso de imóveis públicos poderá ser contratada coletivamente (FERNANDES, 2007).

Além disso, a referida lei federal dispõe ainda que:

Art. 48. Nos casos de programas e projetos habitacionais de interesse social, desenvolvidos por órgãos ou entidades da Administração Pública com atuação

\footnotetext{
${ }^{15}$ ALFONSIN, Betânia. O significado do Estatuto da Cidade para os processos de regularização fundiária no Brasil. In: Regularização fundiária sustentável: conceitos e diretrizes. Brasília: Ministério das Cidades, 2007.

em: <http://www.urbanismo.caop.mp.pr.gov.br/arquivos/File/Livro_Regularizacao_Fundiaria_Plena_Referenc ias_Conceituais.pdf>. Acessado em: 24 de mar. de 2014. p. 87.
} 
específica nessa área, os contratos de concessão de direito real de uso de imóveis públicos:

I - terão, para todos os fins de direito, caráter de escritura pública, não se aplicando o disposto no inciso II do art. 134 do Código Civil;

II - constituirão título de aceitação obrigatória em garantia de contratos de financiamentos habitacionais.

O inciso II visa tornar mais acessível o sistema de crédito e financiamento, assegurando e contribuindo a permanência no terreno. De modo geral, ainda que de forma menos explícita do que foi o caso do instituto da usucapião especial urbana, também quanto ao instituto da concessão de direito real de uso, o Estatuto da Cidade promoveu avanços importantes na ordem jurídica e social brasileira (FERNANDES, 2007).

Ainda assim, faz-se importante ressaltar que devido a razões jurídicas, políticas e ambientais a seção do Estatuto da Cidade que previa a regulamentação de um instrumento denominado concessão de uso especial para fins de moradia em terras públicas foi vetada pelo Presidente da República. Sendo assim, devido às mobilizações do FNRU entre outros motivos, em setembro de 2001 foi expedida a Medida Provisória $n^{\circ}$ 2.220, a qual reconheceu, em determinadas condições e respeitados certos critérios ambientais, o direito subjetivo (e não apenas como prerrogativa da administração pública) dos ocupantes de imóveis de propriedade pública - inclusive municipal - à concessão de uso especial para fins de moradia. Além disso, a Medida Provisória também estabeleceu em que condições o poder público municipal pode promover a remoção dos ocupantes de áreas públicas para outras áreas mais adequadas, sobretudo do ponto de vista ambiental (FERNANDES, 2010).

Ainda sobre as características da concessão de uso especial para fins de moradia, importante transcrever as claras observações da jurista Betânia Alfonsin:

Trata-se de um direito real, ou seja, um direito oponível a terceiros e não apenas ao concedente que terá por título um contrato entre o Poder Público e o ocupante da área pública ou ainda uma sentença judicial. Em ambos os casos, a concessão do uso deverá ser levada a registro em cartório, para ter eficácia erga omnes, ou seja, para aperfeiçoar-se como direito real.

0 que se concede ao ocupante, note-se, não é a propriedade do bem. Essa permanecerá em poder da administração pública. 0 que se outorga é a concessão de um dos poderes inerentes ao direito de propriedade: o direito de usar o bem. Além disso, o direito será concedido apenas uma vez a cada beneficiário. Observe-se, no entanto, que do ponto de vista dos moradores, o dispositivo é um avanço, já que o Poder Público sempre teve a faculdade de fazer a concessão e não a obrigação que passa a ter, a partir da promulgação da lei ${ }^{16}$.

${ }^{16}$ ALFONSIN, Betânia. O significado do Estatuto da Cidade para os processos de regularização fundiária no Brasil. In: Regularização fundiária sustentável: conceitos e diretrizes. Brasília: Ministério das Cidades, 
A concessão de uso especial para fins de moradia tornou-se direito subjetivo dos ocupantes de baixa-renda de áreas públicas, obrigando o Poder Público a declarar o direito via ato administrativo - por óbvio em situações de recusa ou omissão do Executivo, cabe ação judicial para garantia do direito assegurado em lei, conforme Nelson Saule Júnior:

A concessão de uso deixa de ser uma faculdade do Poder Público para efeito de promover a regularização fundiária das áreas ocupadas pela população de baixa renda. Esta norma constitucional, de forma idêntica ao usucapião urbano, caracteriza a concessão de uso como direito subjetivo, que deve ser declarado por via administrativa ou pela via judicial, mediante provocação dos interessados, nos termos do art. $6^{\circ}$ da MP. De acordo com este artigo, o título de concessão de uso especial para fins de moradia será obtido pela via administrativa perante o órgão competente da Administração Pública ou, em caso de recusa ou omissão deste, pela via judicial ${ }^{17}$.

$\mathrm{Na}$ oportunidade do pedido de concessão, deverá o interessado provar que se enquadra nos requisitos legais, quais sejam: a área é situada no perímetro urbano e que é utilizada com fins de moradia. Em seguida, passará a correr prazo (12 meses) para o proprietário do bem (Poder Público) decidir o pedido. Em caso de indeferimento, o ocupante deverá buscar a tutela via judicial, situação em que a sentença servirá de título para fins de registro em cartório de registro de imóveis. Em ambas as vias (administrativa e judicial) deverá haver o registro da concessão em cartório a fim de torná-la um direito real, oponível a terceiros, e que, portanto, terá papel fundamental na garantia da segurança da posse (ALFONSIN, 2007).

Além disso, na já referida MP 2.220/2001 foram previstos mecanismos e limites para as concessões, conforme Alfonsin:

A Medida Provisória, embora estabeleça um direito que in genere beneficia os ocupantes de área pública que atendam aos requisitos da lei, não ignora as mazelas da produção das cidades brasileiras e não é conivente com situações que acarretem risco de vida ou à saúde dos ocupantes. Nesses casos, o Poder Público fica obrigado a garantir o direito de moradia em outro local em que haja condições de habitabilidade adequadas

Para outros casos polêmicos, a Medida Provisória facultou aos poderes públicos conceder o uso para fins de moradia em outro imóvel público: quando a área ocupada for de uso comum do povo; anteriormente destinada a projeto de urbanização; de interesse da defesa nacional, ou de preservação ambiental e de

2007. Disponível em:

<http://www.urbanismo.caop.mp.pr.gov.br/arquivos/File/Livro_Regularizacao_Fundiaria_Plena_Referenc ias_Conceituais.pdf $>$. Acessado em: 24 de mar. de 2014. p. 88.

17 SAULE JÚNIOR, Nelson. A proteção jurídica da moradia nos Assentamentos Irregulares. Porto Alegre: Sérgio Antônio Fabris Editor, 2004, p.412. 

represas e obras congêneres ou situada em via de comunicação ${ }^{18}$.

\section{PAPEL DO PODER PÚBLICO NA GARANTIA DA SEGURANÇA DA POSSE E EFETIVAÇÃO DO DIREITO À MORADIA}

A Constituição Federal assegura que as normas definidoras dos direitos e garantias fundamentais têm aplicação imediata. Desse modo, imperioso se faz a implementação do Direito Social à Moradia através de políticas públicas sólidas, como modo de amenizar as históricas diferenças sociais no país como aponta o constitucionalista CANOTILHO:

os direitos sociais realizam-se através de políticas públicas ('política da segurança social', 'política da saúde', 'política do ensino'), - e no meu entender política da habitação -, orientados segundo o princípio básico e estruturante da solidariedade social. Designa-se, por isso, política de solidariedade social o conjunto de dinâmicas político-sociais através das quais a comunidade política (Estado, organizações sociais, instituições particulares de solidariedade social e, agora, a Comunidade Européia) gera, cria e implementa protecções institucionalizadas no âmbito económico, social e cultural ${ }^{19}$.

Igualmente, o direito à moradia significa não ser privado arbitrariamente de uma habitação e de conseguir uma; e, por outro lado, significa o direito de obter uma, o que exige medidas e prestações estatais adequadas à sua efetivação (CANOTILHO; MOREIRA, apud SILVA, 2008, p. 382).

Conforme bem preceitua nossa Suprema $\operatorname{Corte}^{20}$ :

A interpretação da norma programática não pode transformá-la em promessa constitucional inconseqüente [...] sob pena de o Poder Público, fraudando justas expectativas nele depositadas pela coletividade, substituir, de maneira ilegítima, o cumprimento de seu impostergável dever, por um gesto irresponsável de infidelidade governamental ao que determina a própria Lei Fundamental do Estado.

\footnotetext{
${ }^{18}$ ALFONSIN, Betânia. O significado do Estatuto da Cidade para os processos de regularização fundiária no Brasil. In: Regularização fundiária sustentável: conceitos e diretrizes. Brasília: Ministério das Cidades, 2007. Disponível

em: <http://www.urbanismo.caop.mp.pr.gov.br/arquivos/File/Livro_Regularizacao_Fundiaria_Plena_Referenc ias_Conceituais.pdf>. Acessado em: 24 de mar. de 2014. p. 87.p.91.

${ }_{19}$ CANOTILHO, J. J. Gomes. Direito Constitucional e Teoria da Constituição. Coimbra: Almedina, 1999. p. 518.

${ }^{20}$ RE 271286 AgR, Relator(a): Min. CELSO DE MELLO, Segunda Turma, julgado em 12/09/2000, ACÓRDÃO ELETRÔNICO DJ 24-11-2000 PP-00101 EMENT VOL-02013-07 PP-01409.
} 
$E$, em recente julgamento pelo Pleno do mesmo Tribunal, foi salientado o status do direito à moradia, havendo, se não na totalidade, na maioria dos votos, admissão de que se trata de direito fundamental. Portanto, atinge sua eficácia plena em seu duplo aspecto: direito de defesa e direito a prestações, sendo que o último enseja uma postura ativa do Estado, gerando obrigação de entregar ao seu povo prestações de natureza jurídica e material.

Cuidando do primeiro aspecto - direito de defesa -, é relevante transcrever a concepção de CANOTILHO, pela qual:

Os direitos fundamentais cumprem a função de direitos de defesa dos cidadãos sob uma dupla perspectiva: (1) constituem, num plano jurídico-objetivo, normas de competência negativa para os poderes públicos, proibindo fundamentalmente as ingerências destes na esfera jurídica individual; (2) implicam, num plano jurídico-subjetivo, o poder de exercer positivamente direitos fundamentais (liberdade positiva) e de exigir omissões dos poderes públicos, de forma a evitar agressões lesivas por parte dos mesmos. (liberdade negativa) ${ }^{21}$.

Os direitos sociais têm natureza coletiva, dependem e regram situações a serem criadas pelo Poder Público e sua eficácia está relacionada a uma atuação conjunta dos poderes Executivo, Legislativo e Judiciário. Eles são direitos públicos subjetivos e devem ser alcançados através da justiça distributiva, vez que não são fruíveis individualmente.

Neste sentido, é válido lembrar que a segurança da posse é um ponto central do direito à moradia, pois sem ela o direito à moradia vai estar em permanente ameaça, e o risco de despejo ou deslocamento forçado será sempre iminente.

Para tanto, faz-se importante destacar o papel do Poder Público Municipal na concretização de políticas de regularização fundiária, conforme resta demonstrado na cartilha institucional do Ministério das Cidades, Regularização Fundiária Urbana:

A Lei $n^{\circ} 11.977 / 2009$ explicitou a atribuição dos municípios na definição dos procedimentos de regularização fundiária em seus territórios, que deve ser feita por meio de uma norma municipal, podendo ser uma lei, um decreto, ou ambos. Toda a matéria que depender de autorização legislativa, como a desafetação ou a alienação de bens públicos para promoção de regularização fundiária, por exemplo, deve ser prevista em lei. Já os temas estritamente relacionados às rotinas de trabalho da administração municipal, como a forma de instrução de processos administrativos, processamento de pedidos de regularização, entre outros, podem ser definidos num decreto municipal editado pelo prefeito, ou por

${ }^{21}$ CANOTILHO, J. J. Gomes. Direito Constitucional e Teoria da Constituição. Coimbra: Almedina, 1999. p. 401. 
norma inferior. Para definir a melhor forma de disciplinar a regularização fundiária em seu território, o município deve verificar também o que a lei do Plano Diretor e os planos setoriais relacionados ao tema, como é o caso do Plano Local de Habitação de Interesse Social, estabelecem sobre o assunto ${ }^{22}$.

Clara é a necessidade de o Executivo Municipal criar ou mesmo aplicar mecanismos já existentes com fins de garantir o direito fundamental à moradia à população de baixa renda, posto que a própria Constituição determina que um dos objetivos da República Federativa do Brasil é reduzir as desigualdades sociais e regionais (CONSTITUIÇÃO FEDERAL, artigo $3^{\circ}$, inciso III). Sendo assim, implantar e elaborar políticas públicas firmes, sólidas e amplas de regularização fundiária é de fundamental importância para a construção de uma sociedade mais justa e igualitária.

Além disso, conforme preceitua José Afonso da Silva (2012),

o Direito à Moradia tem uma face que exige prestações positivas do Estado, a qual consiste no direito de obter uma moradia digna e adequada, revelando-se como um direito positivo de caráter prestacional, porque legitima a pretensão do seu titular à realização do direito por via de ação positiva do Estado. É nessa ação positiva que se encontra a condição de eficácia do direito à moradia. E ela está prevista em vários dispositivos de nossa Constituição, entre os quais se destaca 0 art. $3^{\circ}$, que define como objetivos fundamentais da República Federativa do Brasil construir uma sociedade justa e solidária, erradicar a marginalização - e não há marginalização maior do que não se ter um teto para si e para sua família -, e promover o bom de todos, o que pressupõe, no mínimo, ter onde morar dignamente.

Ademais, a Constituição Federal conferiu competência comum da União, Estados, Distrito Federal e dos Municípios para promover programas de construção de moradias e a melhoria das condições habitacionais e de saneamento (art. 23, IX). A contrapartida dessa competência é precisamente o direito de todos à moradia, incumbindo, assim, àquelas entidades do Poder Público promover tais providências para a satisfação desse direito em relação à população que, por deficiência econômica, não pode provê-lo por seus próprios meios (SILVA, 2012).

\footnotetext{
${ }^{22}$ REGULARIZAÇÃO FUNDIÁRIA URBANA: como aplicar a Lei Federal $n^{\circ} 11.977 / 2009$ - Ministério das Cidades, Secretaria Nacional de Habitação e Secretaria Nacional de Acessibilidade e Programas Urbanos. Brasília, 2012. Disponível em: <http://www.urbanismo.caop.mp.pr.gov.br/arquivos/File/Regularizacao_Fundiaria/cartilha_11977.pdf>. Acessado em: 25 de fev. de 2014. P. 36.
} 
Sendo assim, resta claro o dever do Poder Público em assegurar a permanência de ocupantes de áreas públicas e privadas consolidadas no tempo, posto que a garantia do direito à moradia não necessariamente tem a ver com a titulação da propriedade privada individual.

\section{CONCLUSÃO}

Conforme já expressado no decorrer do trabalho, a proliferação da moradia constituída em assentamentos informais, em números, maiores que o crescimento da própria moradia formalizada demonstra que a posse como meio de acesso à moradia é o padrão adotado pela maioria da população pobre no Brasil. A mudança de paradigma foi realizada por parte significativa da sociedade que não detém condições de aquisição pelo mercado imobiliário.

O Estado cala. Isenta-se duas vezes. Uma quando não propõe meios de acesso ao direito básico à moradia, outra quando autoriza e legitima os despejos forçados a quem não se adequou às regras do mercado.

Os mecanismos de política urbana (ainda que com suas limitações) estão disponíveis ao Poder Público que, por sua vez, não tem o interesse político-ideológico de assegurar e legitimar a posse às populações de baixa renda, visto que estão submetidos às regras do capital.

Neste contexto, a camada social que não detém de renda para acesso à moradia “digna e segura", resta sujeita a despejos forçados com a negação de seu estado de direito. Estas violações aos direitos fundamentais são cotidianas e habituais em nosso país. Contraditoriamente, o Brasil tem entre seus objetivos fundamentais, "erradicar a pobreza e a marginalização, reduzir as desigualdades, construir uma sociedade livre, justa e solidária", todavia sua ação está pautada em uma "não-ação”, “não-intervenção". Esta omissão estatal agrava e contribui para perpetuação de um estado societário de não direito.

Portanto, ressalta-se a essencialidade de programas públicos que sejam cumpridos com rigor, que garantam à moradia adequada protegendo à posse dos ocupantes de assentamentos consolidados no tempo e na história. A quebra de paradigma efetuada pelo povo deve ser legitimada pelo Estado, na intenção de mitigar as consequências do mercado inerente ao sistema capitalista. 


\section{REFERÊNCIAS}

ALFONSIN, Betânia e FERNANDES, Edésio (org.). Direito à moradia e Segurança da Posse no Estatuto da Cidade. Belo Horizonte: Fórum, 2004.

ALFONSIN, Betânia. O significado do Estatuto da Cidade para os processos de regularização fundiária no Brasil. In: Regularização fundiária sustentável: conceitos e diretrizes. Brasília: Ministério das Cidades, 2007. Disponível em:

<http://www.urbanismo.caop.mp.pr.gov.br/arquivos/File/Livro_Regularizacao_Fundiaria_Plena Referencias_Conceituais.pdf>. Acessado em: 24 de mar. de 2014.

ALFONSIN, Betânia; FERNANDES, Edésio. A Construção do Direito Urbanístico Brasileiro: desafios, histórias, disputas e atores. In: Coletânea de Legislação Urbanística. Belo Horizonte: Fórum, 2010.

ANCONA, Ana Lúcia. Como delimitar e regulamentar Zonas Especiais de Interesse Social. Brasília: Ministério das Cidades, 2009. Disponível em:

<http://www.sst.sc.gov.br/arquivos/id_submenu/230/guia_zeis_final.pdf>. Acessado em: 25 de mar. de 2014.

CANOTILHO, J. J. Gomes. Direito Constitucional e Teoria da Constituição. Coimbra: Almedina, 1999.

FERNANDES, Edésio. O Estatuto da Cidade e a Ordem Jurídico-Urbanística. In: Estatuto da Cidade Comentado. CARVALHO, Celso Santos e ROSSBACH, Ana Claudia (org.). São Paulo: Ministério das Cidades, 2010.

FERNANDES, Edésio. Perspectivas para renovação das políticas de legalização das favelas no Brasil. Brasília: Ministério das Cidades, 2007. Disponível em:

<http://www.urbanismo.caop.mp.pr.gov.br/arquivos/File/Livro_Regularizacao_Fundiaria_Plena Referencias_Conceituais.pdf > Acessado em: 04 de mar. de 2014.

FERNANDES, Edésio. Regularização de assentamentos informais: o grande desafio dos governos e da sociedade. In: CARVALHO, Celso Santos (coord). Acesso à terra urbanizada: implementação de planos diretores e regularização fundiária plena. Florianópolis: UFSC; Brasília: Ministério das Cidades, 2008.

FERNANDES, Edésio. Regularização de Assentamentos Informais: o grande desafio dos municípios, da sociedade e dos juristas brasileiros. Brasília: Ministério das Cidades, 2007. Disponível em:

<http://www.urbanismo.caop.mp.pr.gov.br/arquivos/File/Livro_Regularizacao_Fundiaria_Plena Referencias_Conceituais.pdf> Acessado em: 24 de fev. de 2014.

LEI N ${ }^{\circ} 11.977$, de 7 de Julho de 2009. Disponível em:

<http://www.planalto.gov.br/ccivil_03/_ato2007-2010/2009/lei//11977.htm>. Acessado em: 10 de fev. de 2014. 
LEI N ${ }^{\circ} 10.257$, de 10 de Julho de 2001. Disponível em:

<http://www.planalto.gov.br/ccivil_03/leis/leis_2001/l10257.htm>. Acessado em: 11 de jan. de 2014.

OSÓRIO, Letícia Marques. Direito à Moradia Adequada na América Latina. In: ALFONSIN, Betânia e FERNANDES, Edésio. Direito à Moradia e Segurança da Posse no Estatuto da Cidade: diretrizes, instrumentos e processos de gestão. Belo Horizonte: Fórum, 2006.

REGULARIZAÇÃO FUNDIÁRIA URBANA: como aplicar a Lei Federal $n^{\circ}$ 11.977/2009 - Ministério das Cidades, Secretaria Nacional de Habitação e Secretaria Nacional de Acessibilidade e Programas Urbanos. Brasília, 2012. Disponível em:

<http://www.urbanismo.caop.mp.pr.gov.br/arquivos/File/Regularizacao_Fundiaria/cartilha_119 77.pdf>. Acessado em: 25 de fev. de 2014.

ROLNIK, Raquel. Como mapear as áreas irregulares. In: ALFONSIN, Betânia de Moraes Et al (coord.). Regularização da Terra e Moradia: o que é e como implementar. São Paulo: Instituo Polis, 2002. Disponível em: <http://www.polis.org.br/uploads/949/949.pdf> Acessado em: 24 de jan. de 2014.

ROLNIK, Raquel. Informe de la Relatora Especial sobre uma vivenda adecuada como elemento integrante del derecho a um nível de vida adecuado y sobre el derecho de no discriminación a este respecto. 2012. Disponível em:

<http://www.ohchr.org/Documents/HRBodies/HRCouncil/RegularSession/Session22/A.HRC.22.4 6_sp.pdf $>$. Acessado em: 25 de mar. de 2014.

SALLES, Venicio. Usucapião Administrativa: Lei 11.977/2009. Disponível em: <http://iregistradores.org.br/usucapiao-administrativa-lei-119772009/>. Acessado em: 25 de jan. de 2014.

SAULE JÚNIOR, Nelson. A proteção jurídica da moradia nos Assentamentos Irregulares. Porto Alegre: Sérgio Antônio Fabris Editor, 2004.

SILVA, José Afonso. Curso de Direito Constitucional Positivo. $35^{\mathrm{a}}$ ed. São Paulo: Malheiros Editores Ltda, 2012.

Recebido em: 01.05.2014

Revisões em: 04.06.2014

Aprovado em: 03.07.2014 